\title{
The Determinants Of Job Satisfaction Among Registered Nurses
}

David E. Kalist, Shippensburg University, USA

Ifeakandu N. Okoye, Florida A\&M University, USA

\begin{abstract}
This study empirically examines the determinants of registered nurses' job satisfaction. Our results indicate that the most satisfied nurse is a young CRNA who is female, married, and not in a union. The profile of the least satisfied nurse is a staff nurse who is male, non-married, unionized, and earns a low salary and works many hours.
\end{abstract}

Keywords: Registered Nurses; Job Satisfaction; Hospitals; Union; Logit

\section{INTRODUCTION}

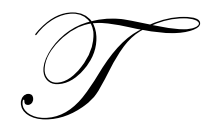

he purpose of this study is to examine job satisfaction of registered nurses (RNs) by using a large nationally representative dataset. Understanding job satisfaction is vital to the success of any organization. Although technology is increasingly used in health care, nurses are and will continue to be the health sector's dominant input. Therefore, analyzing job satisfaction of RNs is of special interest because job satisfaction is a good predictor of job quits (Hamermesh, 1977; Freeman, 1978) and absenteeism (Fletcher, 2001). A satisfied RN is more likely to be committed to her job and less likely to quit or miss work. There is an economic component to dissatisfied workers: The cost of hiring a replacement medical/surgical nurse and a specialty nurse are $\$ 42,000$ and $\$ 64,000$, respectively (Aiken, Clarke, Sloane, Sochalski, \& Silber, 2002).

Job satisfaction can be influenced by a variety of factors such as personal needs and job characteristics, which includes the physical environment, number of hours worked, the job's stress level, workload, and relationships with colleagues and supervisors. Characteristics such as gender, education, age, and sex affect job satisfaction of RNs, too (Clark, 1996, 1997; Aiken, et al., 2001). Health care administrators should recognize that job satisfaction implies a nursing workforce that is not only motivated, but also committed to providing high quality patient care services. Failure by health care administrators to adequately address the individual and job characteristics as well as the personal needs of their staff may result in job dissatisfaction, leading to poor performance, frequent absences from work, and high turnover.

\section{JOB SATISFACTION IN THE HEALTH CARE INDUSTRY}

Studies of job satisfaction within the health care industry have focused more on job characteristics of nurses and less on their personal characteristics. Stress, low pay, inadequate staffing, unreasonable workload, lack of autonomy, poor support from supervisors, and strained relations with coworkers are some of the factors often cited as causes of job dissatisfaction among RNs (Fletcher, 2001; Sochalski, 2001; Ingersoll, Olsan, Drew-Cates, DeVinney, \& Davis, 2002; Aiken et al., 2001; Aiken, Clarke, Sloane, Sochalski, \& Silber, 2002; Needleman, Buerhaus, Mattke, Stewart, \& Zelevinsky, 2002; Rogers et al., 2004; Steinbrook, 2002). Aiken et al. (2001) found that U.S. nurses reported the highest levels of dissatisfaction (41\%), whereas job dissatisfaction among nurses in Scotland, England, Canada, and Germany were 38\%, 36\%, 33\%, and 17\% respectively. Surprisingly, however, and for all the countries in the study, a greater proportion of the nurses who planned to quit within one year of the survey were under 30 years of age. Given the ageing workforce, this result has implications for health care administrators: (1) that improving job characteristics can no longer be ignored, and (2) that meaningful efforts should be placed on retention of satisfied older and more experienced RNs to serve as mentors to younger RNs. 
In another study, Aiken, Clarke, Sloane, Sochalski, \& Silber (2002) found that $41.5 \%$ of RNs reported dissatisfaction with their job, $43.2 \%$ reported burnout, and that $43 \%$ of those who reported dissatisfaction with their job and burnout, expressed their intent to quit their job within one year of the survey. The high patient-nurse ratio found in most of the hospitals sampled indicated that the workload of employed RNs is unreasonably high, helping to explain the results. Some previous studies have shown that age, primary nursing role, employment setting were significant determinants of job satisfaction of. In particular, Ingersoll, Olsan, Drew-Cates, DeVinney, \& Davis (2002) found that RNs who are aged 50 and older were significantly more satisfied than younger registered nurses, that nurses employed in school settings were more satisfied than those employed in other settings like hospitals, that nurse educators have the highest job satisfaction than any other group, and Advanced Practice Nurses (APN) were more satisfied than administrators. Furthermore, the authors noted that nurses 30 years of age and younger were more likely to leave their current job within the next twelve months.

Shields \& Ward (2001) investigated the determinants of job satisfaction of nurses in England. Their study showed that absolute pay is positively correlated with job satisfaction. They also found that married nurses were more satisfied with their work than those not married, that there is a U-shaped relationship between age and job satisfaction. This implies that older nurses are less likely to quit since they are more likely to report higher level of job satisfaction. Shields \& Ward (2001) also found that female nurses were more satisfied with their job than male nurses, and that working long hours has a negative and significant effect on job satisfaction. Our study, which uses data from the U.S., finds similar results.

Using data from 10 Southern Michigan hospitals, Fletcher (2001) found that sources of job dissatisfaction reported by RNs included stress, poor support from supervisors, low pay, lack of benefits, high patient-nurse ratio, and poor relations with co-workers. Sochalski's (2002) study found that employment setting significantly affects level of job satisfaction. In particular, nurses who work in hospitals and nursing homes reported lower levels of job satisfaction than nurses working in other settings. Staff nurses, regardless of employment setting, were found to report the lower levels of job satisfaction than nurses working in other positions. Irrespective of employment setting or position, female nurses were more satisfied with their jobs than their male counterparts.

\section{DATA}

The data used in this study are from the National Sample Survey of Registered Nurses (a survey administrated by The Gallup Organization on behalf of the U.S. Department of Health and Human Services), which contains detailed employment information on a sample of RNs as of March 2004. The NSSRN was first conducted in 1977 and then every four years beginning with the 1980 survey. In the 2004 survey, the NSSRN collected data on job satisfaction. ${ }^{1}$ The strengths of the data are its large sample size and that it nationally represents all actively licensed RNs. The 2004 NSSRN contains observations on over 35,000 nurses, and had an overall survey response rate of approximately 70 percent. There are numerous research articles based on the NSSRN, from those studying issues of discrimination to immigration to wage determination-and now job satisfaction.

Job satisfaction is assessed by the following question: "How would you best describe your feelings about your principal nursing position?" A nurse may respond to the question by indicating that she is either extremely satisfied, moderately satisfied, neither satisfied nor dissatisfied, moderately dissatisfied, or extremely dissatisfied. In this paper, we define a satisfied nurse as either extremely or moderately satisfied because human resource managers are more likely concerned with employees who identify with the other categories-which we refer to as dissatisfied nurses.

Descriptive statistics appear in Table 1. To limit heterogeneity, the sample for our analysis is restricted to fulltime RNs, giving a final sample size of over $16,000 \mathrm{RNs}^{2}{ }^{2}$ The first variable in the table lists whether the nurse is satisfied with her position, the outcome variable of interest. Approximately 79 percent of the sample is satisfied (28.2 percent are extremely satisfied and 50.5 percent are moderately satisfied) in their principle nursing position.

\footnotetext{
${ }^{1}$ The data for the 2008 NSSRN are not available as October 2010; however, the 2008 NSSRN continued to survey respondents on job satisfaction.

${ }^{2}$ We also eliminated missing responses and respondents with an annual salary of less than $\$ 10,000$.
} 
This value compares favorably to the preliminary findings of the 2008 NSSRN, which mentions that 81 percent of the RNs are satisfied (U.S. Department of Health and Human Services, Health Resources and Services Administration, 2010). As for the other job satisfaction categories, 7.2 percent of the RNs are neither satisfied nor dissatisfied, 11.2 percent are moderately dissatisfied, and 2.9 percent are extremely dissatisfied.

We use the $t$ test to investigate whether the difference in means is statistically significant between satisfied and dissatisfied RNs. The results are shown in the last column of Table 1. To highlight some of the findings, we observe that a greater proportion of satisfied RNs are female, married, and white. In addition satisfied RNs tend to work less and make more money than dissatisfied RNs. On the other hand, a greater proportion of dissatisfied RNs are union members, staff nurses, and employed in hospitals.

Table 1. Descriptive Statistics

\begin{tabular}{|c|c|c|c|c|c|c|c|}
\hline & \multicolumn{2}{|c|}{ Entire Sample } & \multicolumn{2}{|c|}{ Satisfied Nurses } & \multicolumn{2}{|c|}{ Dissatisfied Nurses } & \multirow[b]{2}{*}{$t$ test } \\
\hline & Mean & Std. Dev. & Mean & Std. Dev. & Mean & Std. Dev. & \\
\hline Satisfied with Position & 0.7867 & 0.4097 & 1 & 0 & 0 & 0 & \\
\hline Union Status & 0.1503 & 0.3574 & 0.1442 & 0.3513 & 0.1729 & 0.3783 & $* * *$ \\
\hline Age & 45.0132 & 10.1428 & 45.0781 & 10.1467 & 44.7741 & 10.1260 & \\
\hline Married & 0.6764 & 0.4679 & 0.6893 & 0.4628 & 0.6288 & 0.4832 & $* * *$ \\
\hline Never Married & 0.1130 & 0.3166 & 0.1061 & 0.3080 & 0.1384 & 0.3454 & $* * *$ \\
\hline Black & 0.0552 & 0.2284 & 0.0527 & 0.2234 & 0.0645 & 0.2456 & $* * *$ \\
\hline White & 0.8984 & 0.3021 & 0.9024 & 0.2967 & 0.8835 & 0.3209 & $* * *$ \\
\hline Hispanic & 0.0178 & 0.1322 & 0.0178 & 0.1322 & 0.0178 & 0.1324 & \\
\hline Children aged $<6$ & 0.1274 & 0.3334 & 0.1306 & 0.3370 & 0.1154 & 0.3195 & $* *$ \\
\hline Children aged 6-18 & 0.3507 & 0.4772 & 0.3553 & 0.4786 & 0.3335 & 0.4715 & $* *$ \\
\hline Female & 0.9244 & 0.2644 & 0.9303 & 0.2546 & 0.9024 & 0.2968 & $* * *$ \\
\hline Annual Hours of work & 2197.6720 & 530.5914 & 2188.8370 & 519.9517 & 2230.2480 & 566.9930 & $* * *$ \\
\hline Salary (in 10,000 s) & 5.9082 & 2.2520 & 5.9651 & 2.3172 & 5.6981 & 1.9791 & $* * *$ \\
\hline Urban location & 0.7781 & 0.4155 & 0.7737 & 0.4184 & 0.7942 & 0.4043 & $* * *$ \\
\hline \multicolumn{8}{|l|}{ Nursing Position } \\
\hline Administrator & 0.0787 & 0.2693 & 0.0867 & 0.2814 & 0.0492 & 0.2163 & \\
\hline Consultant & 0.0141 & 0.1180 & 0.0148 & 0.1209 & 0.0115 & 0.1067 & \\
\hline Supervisor & 0.0365 & 0.1876 & 0.0371 & 0.1891 & 0.0342 & 0.1819 & \\
\hline Faculty/Instructor & 0.0273 & 0.1628 & 0.0301 & 0.1709 & 0.0167 & 0.1281 & $* * *$ \\
\hline Head Nurse & 0.0850 & 0.2789 & 0.0898 & 0.2860 & 0.0673 & 0.2506 & $* * *$ \\
\hline Staff Nurse & 0.5387 & 0.4985 & 0.5132 & 0.4998 & 0.6331 & 0.4820 & $* * *$ \\
\hline Nurse Practitioner & 0.0420 & 0.2006 & 0.0460 & 0.2094 & 0.0273 & 0.1631 & $* * *$ \\
\hline Midwife & 0.0028 & 0.0531 & 0.0031 & 0.0558 & 0.0017 & 0.0415 & \\
\hline Clinical Specialist & 0.0142 & 0.1182 & 0.0148 & 0.1209 & 0.0118 & 0.1080 & \\
\hline CRNA & 0.0107 & 0.1031 & 0.0125 & 0.1111 & 0.0043 & 0.0656 & $* * *$ \\
\hline Research & 0.0092 & 0.0955 & 0.0092 & 0.0955 & 0.0092 & 0.0955 & \\
\hline Private Duty & 0.0024 & 0.0489 & 0.0026 & 0.0507 & 0.0017 & 0.0415 & \\
\hline Informatics & 0.0052 & 0.0716 & 0.0054 & 0.0732 & 0.0043 & 0.0656 & \\
\hline Home Health & 0.0113 & 0.1057 & 0.0109 & 0.1040 & 0.0127 & 0.1118 & \\
\hline Surveyor/Auditor & 0.0066 & 0.0812 & 0.0070 & 0.0835 & 0.0052 & 0.0718 & \\
\hline Patient Coordinator & 0.0659 & 0.2481 & 0.0667 & 0.2494 & 0.0630 & 0.2430 & \\
\hline Clinician & 0.0280 & 0.1650 & 0.0290 & 0.1677 & 0.0245 & 0.1545 & \\
\hline \multicolumn{8}{|l|}{ Practice Setting } \\
\hline Hospital & 0.5575 & 0.4967 & 0.5409 & 0.4983 & 0.6190 & 0.4857 & $* * *$ \\
\hline Nursing Home & 0.0755 & 0.2642 & 0.0741 & 0.2620 & 0.0806 & 0.2722 & \\
\hline Nurse Education & 0.0270 & 0.1619 & 0.0285 & 0.1664 & 0.0213 & 0.1444 & $* *$ \\
\hline Public Health & 0.1039 & 0.3052 & 0.1091 & 0.3118 & 0.0849 & 0.2788 & $* * *$ \\
\hline School Health & 0.0262 & 0.1596 & 0.0292 & 0.1683 & 0.0150 & 0.1214 & $* * *$ \\
\hline Occupational Health & 0.0098 & 0.0983 & 0.0108 & 0.1032 & 0.0060 & 0.0775 & $* *$ \\
\hline Ambulatory Care & 0.1224 & 0.3278 & 0.1309 & 0.3373 & 0.0912 & 0.2880 & $* * *$ \\
\hline Insurance & 0.0268 & 0.1614 & 0.0258 & 0.1586 & 0.0302 & 0.1712 & \\
\hline Planning/Licensing Agency & 0.0049 & 0.0699 & 0.0048 & 0.0694 & 0.0052 & 0.0718 & \\
\hline Observations & 16288 & & 12813 & & 3475 & & \\
\hline
\end{tabular}

Notes: The last column reports the statistical significance from a two sample $t$ test that differences in means between satisfied and dissatisfied nurses equal zero. ${ }^{* * * S t a t i s t i c a l l y ~ s i g n i f i c a n t ~ a t ~ t h e ~} 1$ percent level; **Statistically significant at the 5 percent level. 


\section{METHODS AND RESULTS}

We used logit regression to examine the factors related to $\mathrm{RN}$ job satisfaction. The dichotomous dependent variable is 1 for RNs who are either extremely or moderately satisfied with their job and 0 for those who report neither being satisfied nor dissatisfied, moderately dissatisfied, or extremely dissatisfied. Our independent or explanatory variables in the regressions on job satisfaction control for union status, age, marital status, race, ethnicity, presence of children, sex, hours of work, annual salary, and whether the RN is located in an urban or rural setting. In labor economics, there is a large literature on the effect of union status on job satisfaction. To add to this literature, we create a dummy variable for union status to see whether there is a negative relationship between union status and job satisfaction, as found in most of the literature. We use age and age squared to control for the possibility that age affects job satisfaction nonlinearly. Marital status is measured by two dummy variables: married and never married, with the omitted category including widowed, divorced, and separated. There are dummy variables for black and white RNs. A Hispanic dummy variable measures ethnicity. There is one dummy variable if the RN has children aged less than 6 and another if she has children aged 6-18. Hours of work measures the annual hours of work, including any overtime work. An urban dummy variable notes whether the RN resides in an urban or rural setting.

Other variables indicate the RN's position. We created 17 dummy variables, one for each principal nursing position: administrator, consultant, supervisor, faculty/instructor, head nurse, staff nurse, nurse practitioner, midwife, clinical specialist, CRNA, research, private duty, informatics, home health, surveyor/auditor, patient coordinator, and clinician (the omitted category is "other" positions). Since job satisfaction may also depend on the RN's practice setting, we use a series of dummy variables to control for whether a RN works in a hospital, nursing home, nurse education, public health, school health, occupational health, ambulatory care, insurance, or planning/licensing agency (the omitted category is "other" positions). Finally, we control for the geographical location of the RN by using eight regional dummy variables (Middle Atlantic, South Atlantic, East South Central, East south Central, East North Central, West North Central, Mountain, and Pacific), where New England is the omitted category.

Table 2 presents the results. It should be noted that the logit regression is weighted by the sampling weight provided in the 2004 NSSRN, and the standard errors are adjusted for heteroscedasticty of unknown form (i.e., we report robust standard errors). The coefficients reported in the table represent marginal effects, giving the change in the predicted probability of job satisfaction from a one-unit change (for dummy variables, it is a discrete change from 0 to 1 ) in the explanatory variable. The first variable that we observe to affect job satisfaction is union status. The marginal effects imply that union members have a 2.4 percent lower probability of job satisfaction, a result consistent with the broader literature on union status and job satisfaction. Surprisingly, many studies find that, regardless of occupation, union employees report less job satisfaction than their nonunion counterparts (Freeman, 1978; Borjas, 1979; Meng, 1990).

One explanation put forth in the literature is the exit-voice hypothesis. As explained by Borjas (2008), unions create a politicized workforce which, in turn, gives union members a platform to voice their discontent, expressing less job satisfaction. Indeed, nurses with concerns about worsening patient care conditions were more accepting of union representation than other nurses (Clark, Clark, Day, \& Shea, 2001). Borjas (2008) notes that union job dissatisfaction may not be real given that union members do not have high quit rates, even after controlling for differences in union-nonunion compensation. Schumacher (1997) provides evidence of lower quit rates for unionized RNs. Hirsch \& Schumacher (1998) suggest that the wage premium for unionized RNs is small, ranging from approximately 1 to 3 percent, which suggests that the low quit rates for unionized RNs is not related to favorable wage differentials.

Hammer \& Avgar (2005) review other explanations for the job satisfaction gap between union and nonunion members. They first discuss the selection effect in which unions are more likely to arise in jobs with unpleasant working conditions. In this case, it is not union membership that causes less job satisfaction, but the unpleasant working conditions that give rise to the union. Another explanation is that union leaders deceive their workers into thinking that they will get better job outcomes, leading to increased expectations that are eventually followed by discontent. Hammer \& Avgar discuss another hypothesis that claims the rigid work rules of unions stifle worker autonomy and may limit opportunities for job promotion. Job satisfaction may vary, too, if there are 
differences in how union and nonunion members evaluate job outcomes. A final explanation is that researchers may fail to control for all relevant variables affecting job satisfaction.

Table 2 Logit Regression: The Determinants of RN Job Satisfaction

\begin{tabular}{|c|c|c|c|}
\hline & Marginal Effect & Std. Error & \\
\hline Union Status & -0.0236 & 0.0120 & $* *$ \\
\hline Age & -0.0059 & 0.0031 & * \\
\hline $\mathrm{Age}^{2}$ & 0.0001 & 0.0000 & $*$ \\
\hline Married & 0.0297 & 0.0097 & $* * *$ \\
\hline Never Married & 0.0006 & 0.0145 & \\
\hline Black & -0.0277 & 0.0238 & \\
\hline White & -0.0030 & 0.0176 & \\
\hline Hispanic & 0.0238 & 0.0255 & \\
\hline Children aged $<6$ & 0.0153 & 0.0123 & \\
\hline Children aged 6-18 & 0.0092 & 0.0088 & \\
\hline Female & 0.0703 & 0.0163 & $* * *$ \\
\hline Annual Hours of work & $-3.2 \mathrm{E}-05$ & 0.0000 & $* * *$ \\
\hline Salary $(\$ 10,000)$ & 0.0098 & 0.0024 & $* * *$ \\
\hline Urban location & -0.0179 & 0.0096 & $*$ \\
\hline \multicolumn{4}{|l|}{ Position } \\
\hline Administrator & 0.0567 & 0.0221 & $* * *$ \\
\hline Consultant & 0.0102 & 0.0377 & \\
\hline Supervisor & 0.0030 & 0.0286 & \\
\hline Faculty/Instructor & 0.0641 & 0.0298 & $* *$ \\
\hline Head Nurse & 0.0146 & 0.0240 & \\
\hline Staff Nurse & -0.0544 & 0.0215 & $* *$ \\
\hline Nurse Practitioner & 0.0247 & 0.0283 & \\
\hline Midwife & 0.0065 & 0.0771 & \\
\hline Clinical Specialist & 0.0403 & 0.0398 & \\
\hline CRNA & 0.1185 & 0.0307 & $* * *$ \\
\hline Research & -0.0471 & 0.0491 & \\
\hline Private Duty & -0.0241 & 0.0858 & \\
\hline Informatics & 0.0346 & 0.0524 & \\
\hline Home Health & -0.0544 & 0.0484 & \\
\hline Surveyor/Auditor & 0.0424 & 0.0449 & \\
\hline Patient Coordinator & -0.0120 & 0.0259 & \\
\hline Clinician & -0.0100 & 0.0393 & \\
\hline \multicolumn{4}{|l|}{ Practice Setting } \\
\hline Hospital & -0.0136 & 0.0187 & \\
\hline Nursing Home & -0.0184 & 0.0238 & \\
\hline Nurse Education & 0.0070 & 0.0351 & \\
\hline Public Health & 0.0299 & 0.0201 & \\
\hline School Health & 0.1001 & 0.0209 & $* * *$ \\
\hline Occupational Health & 0.0852 & 0.0330 & $* * *$ \\
\hline Ambulatory Care & 0.0518 & 0.0186 & $* * *$ \\
\hline Insurance & -0.0576 & 0.0343 & $*$ \\
\hline Planning/Licensing Agency & -0.0589 & 0.0647 & \\
\hline Middle Atlantic & -0.0492 & 0.0186 & $* * *$ \\
\hline South Atlantic & -0.0106 & 0.0162 & \\
\hline East South Central & 0.0136 & 0.0182 & \\
\hline West South Central & 0.0026 & 0.0181 & \\
\hline East North Central & -0.0023 & 0.0167 & \\
\hline West North Central & 0.0109 & 0.0167 & \\
\hline Mountain & -0.0189 & 0.0182 & \\
\hline Pacific & 0.0193 & 0.0170 & \\
\hline Observations & 16,288 & & \\
\hline
\end{tabular}

Notes: The dependent variable equals 1 if the nurse is extremely or moderately satisfied with her principle nursing position and 0 otherwise. The sample is restricted to fulltime RNs and those earning over $\$ 10,000$. The marginal effects are reported, which gives the probability of job satisfaction for a one-unit increase in the explanatory variable. Robust Standard errors are in parentheses. The regression is weighted by the NSSRN's survey sampling weight. ***Statistically significant at 1 percent level; **Statistically significant at the 5 percent level; *Statistically significant at the 10 percent level. 
The negative coefficient on age and the positive coefficient on age-squared highlight the importance for controlling for nonlinearities in age. ${ }^{3}$ The results indicate that job satisfaction is U-shaped with age. For example, the predicted probability of job satisfaction for a RN aged 20,35, 45, and 65 are $0.84,0.80,0.79$, and 0.81 , respectively. By contrast, Norman et al. (2005) found a positive relationship between age and RN job satisfaction. Although their analysis is similar to ours, it appears they did not control for nonlinear effects in their models. Similarly, the findings from the 2008 NSSRN show that job satisfaction increases with age (U.S. Department of Health and Human Services, 2010). These descriptive statistics, unlike our regression based results, do not control for any confounding factors that are correlated with age and job satisfaction, in addition to ignoring nonlinear effects on age and job satisfaction.

To shed light on the differences in findings between our results and those reported by the U.S. Department of Health and Human Services (2010), we estimate two logit regression models that only include explanatory variables for age. The first model regresses job satisfaction on age, and the second model includes age-squared as an additional explanatory variable. Table 3 shows the results. Without controlling for nonlinearities in age, the results indicate a higher probability of job satisfaction for older RNS, consistent with the findings of Norman et al. (2005) and the U.S. Department of Health and Human Services (2010). However, the inclusion of the age-squared term, reveals the U-shaped relationship between job satisfaction and age.

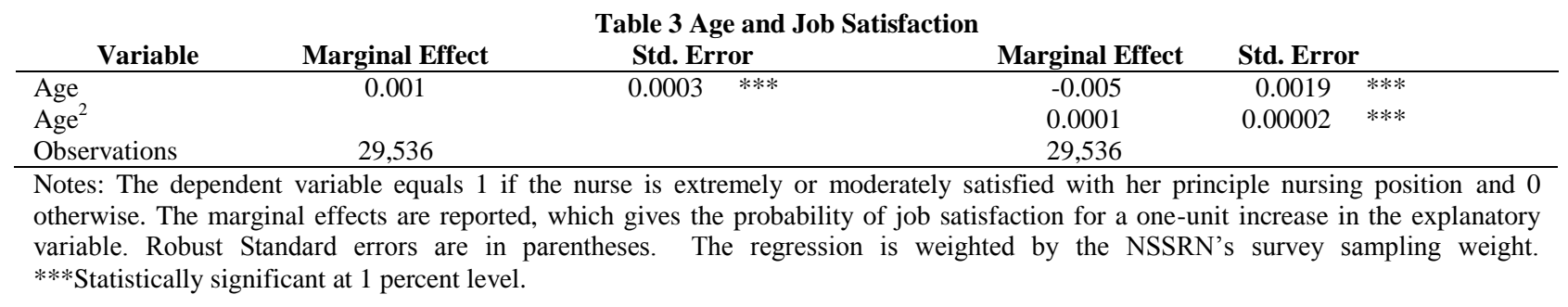

What might explain the U-shaped pattern in job satisfaction? Young RNs may have overly optimistic expectations about their work and profession. When the reality of work does not meet their expectations, they may feel less positive about their job. On the other hand, older RNs, through years of work experience, are more likely to know the job settings that provide them the most satisfaction. Thus, we expect better job matches for older RNs. It should be noted that the U-Shaped pattern of job satisfaction has been found in other occupations (Clark, Oswald, \& Warr, 1996; Blanchflower \& Oswald, 2004).

Marital status is the next variable to have a statistically significant effect on job satisfaction. Married RNs have a 3 percent higher probability of job satisfaction than those who are widowed, divorced, separated, or never married. One explanation is that married RNs are less likely to work for economic reasons, since they are not the sole breadwinner. In other words, because non-married RNs may be their household's sole breadwinner, they may be compelled to work regardless of their job satisfaction. The results in the literature are inconclusive:" with some studies finding married workers are less satisfied than single workers (Gazioglu \& Tansel, 2002) and others finding that married workers are more satisfied than unmarried workers (Clark, 1997).

The explanatory variables for race and ethnicity are not correlated with job satisfaction, given their coefficients are not statically different from zero. In a related article, Shields \& Price (2002) report that ethnic minority nurses who experience discrimination reported lower levels of job satisfaction. The presence of children either aged less than 6 or aged 6-18 has no effect on job satisfaction.

\footnotetext{
${ }^{3}$ The hypothesis that the effects of age and age squared are simultaneously equal to zero is rejected at the 0.10 level (chi-squared $=4.85, \mathrm{p}=0.0886$ ). In a logit regression without the age-squared variable, we find that the coefficient on age is negative but not statistically significant from zero at conventional levels $(\mathrm{p}=0.144)$.
} 
Female RNs appear more satisfied with their job than their male counterparts, since being female is associated with a 7 percent higher probability of job satisfaction. This finding is not too surprising given the large literature that finds greater job satisfaction among females despite the fact that they earn less than men and have less promotion potential than men (Clark 1996, 1997; Sousa-Poza and Sousa-Poza, 2000; Bender, Donohue, \& Heywood, 2005; Clark \& Oswald, 1996, Sloane \& Williams, 2000). One common explanation for the gender gap in job satisfaction is that females have lower job expectations than their male colleagues (Clark, 1997).

The positive coefficient on salary and negative coefficient on hours of work suggest that job satisfaction increases with salary but decreases with hours of work. An additional $\$ 10,000$ of salary increases the probability of job satisfaction by almost 1 percent. Working 400 additional hours a year decreases the probability of job satisfaction by approximately 1.3 percent. This interpretation assumes that all other variables are held constant, including salary. However, it is expected that jobs that require more hours of work will pay compensating wage differentials. Indeed, we find that Spearman's rank correlation coefficient between salary and hours of work is 0.64 ( $p$ value < 0.01). Clark (1997) found that that longer hours of work result in lower job satisfaction.

RNs who reside in an urban area (i.e., metropolitan statistical area) are less likely to report that they are satisfied with their job. This result may be attributable to longer commute times arising from traffic congestion. In a study of nurses working in nursing homes, Coward et al. (1995) did not find a statistically significant relationship between job satisfaction and location. By contrast Coward, Horne, Duncan, \& Dwyer (1992) reported that nurses employed in small rural hospitals are more satisfied than nurses employed in large urban hospitals.

The next set of explanatory variables examines the effect of a RN's principal nursing position on job satisfaction, where the omitted category includes "other" positions. Four of the variables are statistically significant. CRNAs have the highest probability of job satisfaction, whereas staff RNs have the lowest probability of job satisfaction. In fact, compared to staff RNs, CRNAs have an approximately 17 percent higher probability of reported job satisfaction. The large difference in job satisfaction between CRNAs and staff RNs may be explained by CRNAs having more job autonomy. Kalist, Molinari, and Spurr (2011) conclude that "With regard to what the CRNA can do, the scope of practice of CRNAs is well defined and for all practical purposes unrestricted in every State." Terry Wicks, former president of the American Association of Nurse Anesthetists, discusses his experiences as a CRNA: ${ }^{4}$

Nurse anesthetists are the happiest nurses I have ever met. I have traveled North and South, and coast to coast and everywhere I have traveled I see the same thing. CRNAs love their jobs...Being a CRNA is an opportunity to work with highly trained professionals in teams of surgeons (and other physicians at times) [,] nurses, and technicians who are all focused on the same goal, getting the patient safely through their surgical experience. As a CRNA you will be a respected and sought after member of that team.

The positions of administrator and faculty are also positively associated with job satisfaction, although the effect is about half that of CRNAs.

As for the explanatory variables that control for practice setting (the omitted category includes "other" practice settings), the coefficients on hospital and nursing home are negative but not statistically significant. RNs practicing in a school health setting have a 10 percent greater probability of job satisfaction, which is similar to the effect of working in an occupation health setting. Ambulatory care increases job satisfaction by approximately 5 percentage points. The final set of explanatory variables controls for the RN's region of residence. The only coefficient that is statistically significant is for the Middle Atlantic region, indicating that RNs in this region are 5 percentage points less likely to report job satisfaction than those in New England region (the omitted category).

\footnotetext{
${ }^{4}$ http://allnurses.com/pre-crna-inquiry/crna-job-satisfaction-243392.html
} 


\section{SUMMARY}

This study has identified some of the important variables that affect the level of job satisfaction of RNs. According to our results, the factors that affect job satisfaction are age, sex, salary, hours of work, union membership, employment setting, and position. In particular, our study showed that female nurses were more satisfied than male nurses, that married nurses report higher job satisfaction, and that workload (hours of work) and union membership have negative and significant effect on job satisfaction. The data also suggest that job heterogeneity leads to differences in job satisfaction. CRNAs, administrators, and faculty positions are associated with high levels of job satisfaction compared to many other positions especially that of staff nurse. Staff nurses report the lowest levels of job satisfaction.

By indentifying factors related to job satisfaction, the findings of this study should be instructive for health care administrators and nurse managers. For example, knowing that young RNs are likely to experience declining job satisfaction early in their careers may better enable administrators to design policies and programs to counter these effects. Most importantly, they should recognize that improving job satisfaction of registered nurses - their key input, means a workforce that is not only motivated, but also committed to providing high quality patient care services that ultimately leads to increased patient satisfaction. Therefore, to prevent or rather minimize job dissatisfaction of RNs and the resultant low productivity, absenteeism, and high nurse turnover, it is important that hospital administrators focus emphasis on improving job characteristics as well as addressing the personal needs of the registered nurses.

\section{AUTHOR INFORMATION}

Dr. David E. Kalist earned his $\mathrm{PhD}$ in economics at Wayne State University. He is an associate professor in the department of economics at Shippensburg University, teaching courses in health, labor, and sports economics. He has published 19 articles, with many related to nursing, in journals such as Nursing Economic\$, Industrial Relations; Industrial and Labor Relations Review; Health Economics, Policy and Law; Journal of Regulatory Economics; International Journal of Health Care Finance and Economics; and Nursing \& Health Policy Review. E-mail: dekali@ship.edu.

Dr. Ifeakandu N. Okoye is an assistant professor in the department of economics, Florida A\&M University, in Tallahassee, Florida. He teaches principles courses and upper level courses in labor, public finance, economics of managerial finance, health, international trade, and economic development. His research interests are primarily in health and labor economics. E-mail: ifeakandu.okoye@ famu.edu.

\section{REFERENCES}

1. Aiken, L., Clarke, S., Sloane, D., Sochalski, J., Busse, R., Clarke, H., Giovannetti, P., Hunt, J., Rafferty, A. and Shamian, J. (2001), Nurses' report on hospital care in five countries. Health Affairs, 20 (3): 43-53.

2. Aiken, L., Clarke, S., Sloane, D., Sochalski, J., and Silber, J. (2002), Hospital nurse staffing and patient mortality, nurse burnout, and job dissatisfaction. Journal of the American Medical Association, 288 (16): 1987-1993.

3. Bender, K., Donohue, S. and Heywood, J. (2005). Job satisfaction and gender segregation. Oxford Economic Papers, 57: 479-496.

4. Blanchflower, D. and Oswald, A. (2004). Well-being over time in Britain and the USA. Journal of Public Economics, 88:1359-1386.

5. Blegen, M. (1993). Nurses' job satisfaction: a meta-analysis of related variables. Nursing Research, 42: 36 -41 .

6. Borjas, G. (1979), Job satisfaction, wages and unions. Journal of Human Resources 14: 21 - 40.

7. $\quad$ Borjas, G. (2008). Labor Economics. New York: McGraw-Hill.

8. Clark, A. E. (1996). Job satisfaction in Britain. British Journal of Industrial Relations, 34: 189 - 217.

9. Clark, A. E. (1997). Job satisfaction and gender: why are women so happy at work. Labour Economics, $4: 341-372$. 
10. Clark, P. F., Clark, D. A., Day, D. V., \& Shea, D. G. (2001). Healthcare reform and the workplace experiences of nurses: implications for patient care and union organization. Industrial and Labor Relations Review. 55(1). 133-148.

11. Clark, A.E., Georgellis, Y. and Sanfey, P. (1998), Job satisfaction, wage changes and quits: evidence from Germany. Research in Labor Economics, 17: 95-121.

12. Clark, A. E., \& Oswald, A. (1996), Satisfaction and comparison income, Journal of Public Economics, 61: 359-381.

13. Clark, A. E., Oswald, A., Warr, P. (1996). Is job satisfaction U-shaped in age? Journal of Occupational and Organizational Psychology, 69: 57-81.

14. Coward, R. T., Hogan T. L., Duncan, R. P., Horne, C. H., Hilker, M. A., \& Felsen, L. M. (1995). Job satisfaction of nurses employed in rural and urban long-term care facilities. Research in Nursing \& Health. 18(3). 271-284.

15. Coward, R. T., Horne C., Duncan, R. P., \& Dwyer, J. W. (1992). Job Satisfaction Among Hospital Nurses: Facility Size and Location Comparisons. The Journal of Rural Health. 8(4). 255-267.

16. Fletcher, C. E. (2001). Hospital registered nurses' job satisfaction and dissatisfaction. Journal of Nursing Administration, 31(6): 324-331.

17. Freeman, R. B. (1978), Job satisfaction as an economic variable, American Economic Review: Papers and Proceedings, 68, 135-141.

18. Gazioglu, S. and Tansel, A. (2002). Job satisfaction in Britain: individual and job related factors. ERC Working Paper, Department of Economics, Middle East Technical University, Ankara.

19. Hamermesh, D. S. (1977), Economic aspects of job satisfaction, in Ashenfelter, O.C. and Oates, W.E. (Eds.), Essays in Labor Market Analysis, Wiley, New York, 53-72.

20. Hammer, T. H., \& Avgar, A. (2005). The impact of unions on job satisfaction, organizational commitment, and turnover. Journal of Labor Research. 26(2). 241-266.

21. Hirsch, B.T., Schumacher, E.J. (1998). Unions, wages, and skills. Journal of Human Resources. 33(1). 201219.

22. Ingersoll, G. L., Olsan, T., Drew-Cates, J., DeVinney, B., Davis, J. (2002). Nurses' job satisfaction, organizational commitment, and career intent. Journal of Nursing Administration, 32(5): 250-263.

23. Kalist, D. E., Molinari, N. A., \& Spurr, S. J. (2011). Cooperation and conflict between very similar occupations: the case of anesthesia. Health Economics, Policy and Law. 6(2). 237-264

24. Meng, R. (1990). The relationship between unions and job satisfaction. Applied Economics, 22: 1635-1648.

25. Needleman, J., Buerhaus, P., Mattke, S., Stewart, M. and Zelevinsky, K. (2002). Nurse-staffing levels and the quality of care in hospitals. New England Journal of Medicine, 346(22): 1715-1722.

26. Norman, L. D., Donelan, K. Buerhaus, P. I., Willis, G., Williams, M., Ulrich, B. Dittus, R. (2005). The Older Nurse in the Workplace: Does Age Matter? Nursing Economics. 23(6). 282-289.

27. Rogers, A. E., Hwang, WeiTing, Scott, L. D. Aiken, L. H. and Dinges, D. F. (2004) The working hours of hospital staff nurses and patient safety. Health Affairs, 23(4):202-212.

28. Schumacher, E. (1997). Relative wages and exit behavior among registered nurses. Journal of Labor Research. 18(4): 581-592.

29. Shields, M. and Price, S. (2002). Rcial harassment, job satisfaction and intentions to quit: evidence from the British nursing profession. Economica, 69: 295-362.

30. Shields, M. and Ward, M. (2001). Improving nurse retention in the British National Health Services:the impact of job satisfaction on intentions to quit. Journal of Health Economics, 20(5): 677-701.

31. Sloane, P. and Williams, H. (2000). Job satisfaction, comparison earnings and gender. Labour, 14: $473-501$.

32. Sochalski, J. (2001). Nursing's valued resources: critical issues in economics and nursing care. Canadian Journal of Nursing Research, 13: 11-18.

33. Sochalski, J. (2002). Nursing shortage redux: turning the corner on an enduring problem. Health Affairs, 21(5): 157-164.

34. Sousa-Poza, A. and Sousa-Poza, A. A. (2000a). Taking another look at the gender/job satisfaction paradox. KYKLOS, 53:135-152.

35. Steinbrook, R.(2002).Nurses in the crossfire. New England Journal of Medicine, 346(22): 1757-1766.

36. U.S. Department of Health and Human Services, Health Resources and Services Administration (2010). The Registered Nurse Population: Initial Findings from the 2008 National Sample Survey of Registered Nurses 
NOTES 